\title{
MEMPERKENALKAN SEJARAH PAHLAWAN NASIONAL KH. NOER ALI BAGI PESERTA DIDIK MI/SD DI INDONESIA
}

\author{
Milawati ${ }^{1)}$ Anis Fuadah $Z^{2)}$ \\ e-mail: Mila.wati@mhs.uinjkt.ac.id \\ ${ }^{1}$ Mahasiswa Program Studi PGMI FITK UIN Syarif Hidayatullah Jakarta \\ ${ }^{2}$ Dosen Fakultas Ilmu Tarbiyah dan Keguruan UIN Syarif Hidayatullah Jakarta
}

\begin{abstract}
Heroes have a very big role in the process of the struggle for Indonesian independence. One of the national heroes who fought for Indonesian independence is K.H. Noer Ali. K.H. Noer Ali is a national hero from Bekasi, West Java. The spirit of fighting for Indonesian independence has been in his soul since he was a child. K.H. Noer Ali is a charismatic cleric figure who has a major influence during the Dutch and Japanese colonial times, and is a popular nationalist scholar who is loved by the people. K.H. Noer Ali is also an army cleric with the rank of colonel who is a symbol of the struggle of the people of Bekasi. K.H. Noer Ali contributed a lot to the process of Indonesia's struggle, both in the political, religious, socio-cultural and educational fields. K.H. Noer Ali participates in several Islamic organizations and serves as chairman of the MUI. K.H. Noer Ali is a founder of the Attaqwa Islamic boarding school. As a fighter who has a high spirit of nationalism and homeland command, K.H. Noer Ali participated in educating the nation's children by establishing Islamic boarding schools.
\end{abstract}

Keywords : Noer Ali, Hero, Struggle

\section{PENDAHULUAN}

Indonesia memiliki sejarah yang begitu panjang dalam mencapai kemerdekaan, kurang lebih dari 350 tahun indonesia berada di bawah kekuasaan negara-negara asing, telah banyak pahlawan yang gugur dalam peristiwa sejarah ini. Dan telah banyak pahlawan dari berbagai daerah yang mengorbankan harta bahkan jiwa untuk memperjuangkan kemerdekaan indonesia. Sampai akhirnya pada tanggal 17 agustus 1945 diproklamasikan kemerdekaan Indonesia oleh presiden pertama yaitu Presiden Ir. Soekarno.

Dalam rangka mempertahankan dan mewujudkan kemerdekaan Negara Kesatuan Republik Indonesia, dengan melakukan banyak cara, baik dilakukan perorangan maupun sekelompok dengan tujuan membela hak asasi manusia, membela harga diri bangsa, maka seseorang ini disebut pahlawan. Pahlawan nasional merupakan gelar yang diberikan oleh pemerintah untuk tokoh-tokoh yang pernah berjuang atas nama Indonesia dan diberikan sebagai penghargaan tertinggi. Gelar itu diberikan sebagai penghargaan atas tindakan nyata dan pengorbanan yang telah di berikan dan sangat berjasa bagi bangsa dan Negara. Pemerintah berharap dengan 
diberikan gelar tersebut dapat membuat warga indonesia selalu mengingat perjuangan mereka dan perjuangan nya dapat dikenang dan diteladani oleh warga negara indonesia (Ariesta, 2017).

Pahlawan nasional merupkan seseorang yang luar biasa, mulai dari melawan penjajah sampai memajukan bangsa Indonesia. Berkat pejuangan yang sangat heroik akhir nya Indonesia bisa merasakan manis nya kebebasan di tanah lahir nya sendiri. Pahlawan memiliki banyak nilai-nilai dan sikap keteladanan yang bisa kita amalkan dan terapkan dalam kehidupan sehari- hari (Marker \& Indonesia, 2015).

Semangat perjuangan para pahlawan merupakan wujud amal perjuangan yang dipersembahkan sebagai rasa cintanya pada tanah air dan bangsa. Mereka berjuang berdasarkan jiwa dan semangat rela berkorban untuk bangsa indonesia. Telah banyak pahlawan-pahlawan yang gugur dalam perjuangan mempertahankan kemerdekaan Indonesia.

Untuk membangun sebuah bangsa dirasa perlu untuk memupuk rasa nasionalisme perjuangan sejak dini, maka dari itu pengenalan nilai-nilai perjuangan pahlawan nasional harus di asosiasikan kepada peserta didik sekolah dasar. Nilai- nilai perjuangan mengandung arti yaitu tentang nilai sikap, jiwa, dan semangat dari para pejuang yang ikhlas berjuang, pantang menyerah, teguh pendirian memiliki keberanian untuk membela kebenaran serta memiliki akhlak yang baik sehinnga dijadikan sebagai suri tuladan bagi bangsa. Nilai-nilai kepahlawanan perlu di junjung tinggi dan di amalkan dalam kehidupan sehari-hari (Sejarah et al., 2014).

Seperti yang kita ketahui pendidikan nilai-nilai sudah mulai diabaikan sehingga membawa pengaruh yang besar terhadap perilaku peserta didik, yaitu mulai berkurangnya rasa cinta produk tanah air dan lebih menyukai produk luar, mulai pudarnya sikap jujur yang dimliki peserta didik dan mulai hilang nya kesadaran akan nilai-nilai kepahlawanan, naionalisme, da sikap patriotisme (Ii et al., 2018).

Maka dari itu Nilai-nilai kepahlawanan perlu dijunjung tinggi dan diamalkan oleh masyarakat indonesia, terutama harus diterapkan pada anak usia sekolah dasar dalam kegiatan sehari-hari, sebab nilai-nilai kepahlawanan saat ini mengalami penurunan dalam penerapan dan pengamalannya. Oleh sebab itu pengenalan nilai-nilai dan perjuangan pahlawan perlu dilakukan dengan cara mensosialisasikan nilai-nilai kepahlawanan pada generasi muda, terutama peserta didik sekolah dasar. Para guru bisa memberikan pemahaman nilai-nilai kepahlawanan seperti di haruskan memiliki sikap jujur, mandiri, agamis dan sikap rela berjuang. Dengan memberikan pemahaman seperti itu terhadap nilai - nilai kepahlawanan diharapkan dapat meningkatkan semangat para peserta didik untuk selalu menerapkan nya baik di sekolah maupun diluar sekolah (Sejarah et al., 2014).

Dalam memperjuangkan kemerdekaan indonesia tidak dapat dipungkiri ulama dan para santri memliki peran yang besar dalam merebut tanah air dari tangan penjajah, para ulama dan para santri bukan hanya saja rela mengorbankan waktu dan tenaga, namun mereka mengorbankan jiwa dan raganya untuk berjihad di medan perang saat itu. Pada saat itu ulama memiliki peran yang amat besar sehingga menyebabkan para penjajah merasa tidak aman atas kehadiran para ulama, maka pada saat itu para ulama banyak uyang diasingkan dan diusir karena dianggap akan membahayakan kekuasaan para penjajah. Salah satu pahlawan nasional dan ulama 
yang gugur dalam perjuangan kemerdekan adalah K.H. Noer Ali. K.H. Noer Ali merupakan salah satu pahlawan nasional yang berasal dari bekasi. Beliau lahir pada tahun 1914 di ujung malang, memiliki nama Noer Ali yang memiliki arti cahaya yang tinggi, beliau lahir dari pasangan Anwar bin Layu dan Maimunah bin Titarbin. K.H. Noer Ali terlahir dari keluarga yang sederhana, walaupun lahir dari kehidupan yang terbilang memiliki keterbatasan dalam ekonomi, tidak membuat beliau putus asa dalam menuntut ilmu. K.H Noer ali merupakan putra keempat. Beliau memiliki tiga orang kakak dan enam seorang adik. K.H.Noer Ali sejak kecil sudah memiliki citacita kelak ketika dewasa, ia ingin menjadi pemimpin agama, sejak kecil pun semangat dan cinta tanah air bernuansa keagamaan sudah menjadi tekad dalam dirinya, beliau seperti itu karena termotivasi dengan ungkapan yang sering didengar dari guru nya tentang thoyyibatun warobbun ghofur( Negara sejahtera yang dilindungi ALLAH). (Kh \& Alie, 1914)

K.H Noer Ali dalam bidang pendidikan sudah dimulai sejak kecil, pada usia 8 tahun sudah mulai mempelajari mengenal dan belajar mengeja huruf arab, dam mulai memgaji dan meghafal al-qur'an. Pada pendidikan menengah awal K.H Noer Ali mulai menuntut ilmu dengan guru Mughni, pada pengajian ini K.H Noer Ali mndapatkan ilmu lanjutan dari pengajian sebelumnya, seberti ilmu tajwid, Nahwu, tauhid, dan fiqh. Selanjutnya pada pendidikan menengah atas K.H Noer Ali mulai mondok di psantren guru Marzuki, setelah menyelesaikan ke menengah atas K.H Noer Ali mulai melanjutkan pendidikan nya ke jenjang yang lebih tinggi di Mekkah.

K.H. Noer Ali merupakan ulama tentara yang mempunyai pangkat kolonel. Ulama tentara merupakan simbol sebagai perjuangan rakyat bekasi dalam memberantas kolonialisme belanda, jepang hingga pemberontakan PKI waktu itu. Dalam proses kepemimpinannya K.H. Noer Ali kerap bebrapa kali menjadi pimpinan dalam berbagai organisasi diantaranya menjadi komandan batalyon III Hizbullah bekasi dan juga memimpin Markas Pusat Hizbullah Salsabilah (MPHS) Jakarta raya. Selain sebagai pimpinan berbagai organisasi baik di ranah politik, kemasyarakatan, maupun agama K.H. Noer Ali juga merupakan seorang ulama yang mendirikan pondok pesantren Attaqwa. Selain itu K.H. Noer Ali juga merupakan ketua ulama indonesia pada saat itu. K.H. Noer Ali juga merupakan tokoh muslim nasionalis yang mempelopori untuk penyerahan kekuasaan negara federal kepada indonesia lewat deklarasi yang dihadiri sekitar 25 ribu rakyat bekasi dan cikarang.Sejak masih kecil dan ketika belajar di mekkah semangat kebangsaan sudah tumbuh didalam jiwa beliau. Sejak masih muda sifat kepemimpinan beliau sudah terlihat. Setelah kembali ketanah air perjalanannya di ranah politik mulai berkembang, dilihat dengan buktinya K.H. Noer Ali terpilih sebagai ketua umum partai masyumi bekasi, masyumi merupakan salah satu partai politik kala itu. Dalam perjalanannya dipolitik rupanya kemampuan dalam kepemimpnannya sudah tak diragukan lagi terbukti dengan maju dan berkembang yang dialami oleh daerah bekasi dan jawa barat. (Kii, 2011)

Kontribusi K.H. Noer Ali dalam perjuangan ia ikut serta dalam beberapa peperangan yang terjadi, K.H.Noer Ali pun kerap beberapa kali menjadi pimpinan dalam perang tersebut. Selain dalam perjuangan, K.H. Noer Ali pun berkontribusi dalam bidang pendidikan yaitu dengan mendirikan pondok pesantren dan lembaga pendidikan yang saat ini memiliki ratusan cabang di jawa barat. Ini merupakan bukti bahwa K.H.Noer Ali berkontrubusi sangat besar dalam dunia pendidikan dan sampai 
saat ini kita masih merasakan manfaatnya. Ini menjadi bukti kecintaan K.H. Noer Ali dalam memperjuangkan bangsa dengan ikut serta dalam mencerdaskan bangsa.

Ketika begitu banyak perjuangan dan upaya yang telah dilakukan untuk kemerdekaan indonesia dan berbagai kontribusi yang telah diberikan membangun negara dan mewujudkan mimpinya sehingga membuahkan hasil yang sepadan dari perjuangannya. Akhirnya pada bulan Mei tahun 1991 K.H. Noer Ali jatuh sakit dan akhirnya menutup mata pada tanggal 29 januari 1992. (LUBIS, 2020)

K.H. Noer Ali memiliki sikap yang patut kita contoh,yaitu semangat yang tinggi dan gigih dalam membela negara yang beliau tanamkan dalam dirinya sejak beliau kanak-kanak. Beliau memiliki semangat yang tinggi untuk membangun bangsa dan membuat masyarakat di sekitarnya sejahtera dan jauh dari penderitaan. Dalam bidang apapun beliau selalu melakukan apa yang dikerjakan hanya untuk kepentingan masyarakat. Dalam bidang pendidikan misalnya, beliau berusaha agar menjadikan manusia yang cerdas agara dapat ikut serta dalam membangun indonesia lebih baik, dalam bidang ekonomi pun, beliau membangun perekonomian bukan hanya untuk dirinya sendiri melainkan untuk kepentingan dan kesejahteraan masyarakat dan santri- santri nya. K.H Noer Ali sebagai seorang ulama dan sebagai pejuang kemerdekaan, beliau merupakan salah satu tokoh yang meyakini bahwa sesungguh nya pancasila merupakan ideologi nasionalis dan UUD 1945 sebagai dasar Negara. (Kh \& Alie, 1914)

\section{METODE}

Penulisan penelitian ini menggunakan metode penelitian studi pustaka, dengan pengumpulan dan menggunakan data sekunder yaitu dengan melakukan pengumpulan sumber-sumber di media elektronik. Sumber data yang diperoleh dari hasil pengumpulan data yang sesuai dengan bahan kajian yaitu : website, buku, dan jurnal. Kajian ini membahas mengenai biografi KH. Abdul Halim serta perjuangan yang ia lakukan semasa hidupnya. Metode analisis dari data yang sudah diperoleh kemudian di analisa dengan menggunakan metode deskritif. Metode ini dilakukan dengan mendeskripsikan fakta-fakta yang diperoleh dari sumber literature kemudian disajikan secara deskriptif lalu dikembangkan dan diterapkan.

\section{PEMBAHASAN}

\section{Biografi K.H. Abdul Halim}

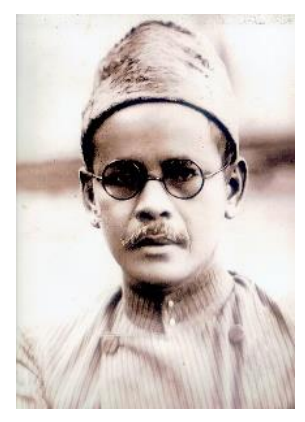


Gambar 1. Sumber: https://santiasromo.or.id/tentang-kami/sejarah-berdiri

Abdul Halim adalah seorang kyai Majalengka-Jawa Barat yang bukan hanya pendiri organisasi Persatuan Ummat Islam (PUI) tetapi termasuk salah seorang pendiri Republik Indonesia. Peranannya tidak saja ditunjukkan pada masa pemerintah Hindia Belanda, tetapi pada masa pemerintah Pendudukan Jepang, dan setelah Indonesia merdeka. Ia pun dikenal telah berhasil mencetak sejumlah ulama dan tokoh yang berpengaruh. Ayahnya, K.H. Iskandar ibn Abdoellah Komar ibn Noersalim, bekerja sebagai Penghulu Kewedanaan Jatiwangi. Ibunya bernama Siti Mutmainah, sebagai ibu rumah tangga biasa. Kuat dugaan, Halim lahir dari keluarga Muslim yang taat. Selain itu, dijumpai informasi, orang tua Halim memiliki hubungan keluarga dengan pemerintah pada waktu itu. Dari pernikahannya dengan Siti Mutmainah, Iskandar dikaruniai delapan orang putra dan putri, masing-masing: 1) Iloh Mardiyah, 2) Empon Kobtiyah, 3) Empeu Sodariyah, 4) Jubaedi, 5) Iping Maesaroh, 6) Hidayat, 7) Siti Sa'diyah, dan 8) si bungsu Halim, biasa disapa sebagai panggilan sayang dalam keluarga, "otong" Sjatori. Iskandar wafat ketika Halim masih kecil.

Sepeninggal Iskandar, Siti Mutmainah ibunya masih berpegang teguh untuk tidak menikah kembali. Dengan seorang diri, ia mengasuh dan membesarkan anakanaknya. Meskipun demikian, Siti Mutmainah mengasuh dan membesarkan mereka dengan dasar-dasar agama Islam yang cukup kuat. Abdul Halim tidak pernah mengikuti jenjang pendidikan formal di sekolah atau madrasah. Abdul Halim belajarnya secara otodidak. Ibunya tak menyekolahkannya ke sekolah Goubernement dikarenakan hanya tokoh terhormat yang dapat bersekolah di tempat tersebut. Berhubung Abdul Halim harus tetap mengemban pendidikan, akhirnya ibunya memasukkan ia ke pesantren dengan alasan pendidikan agama yang sangat kuat yang terlebih dahulu telah ditanamkan ibunya sejak Abdul Halim masih kecil. Ketika usianya mencapai 10 tahun ia sudah dapat membaca al-Qur'an frngan baik sesuai dengan tajwid dan tartil. Pesantren Abdul Halim letaknya di Kampung Cideres, Dawuan. Ketika berada di pesantren Cideres ia bergaul dengan teman-temannya. Berkat pergaulannya ia pun berlatih membaca dan menulis huruf latin serta bahasa Belanda kepada Van Verhoeven.

Pendidikan al-Qur'an di pesantren Kampung Cideres diselesaikan Abdul Halim dalam satu tahun. Setelah lulus, ia tak berhenti belajar melainkan ia tetap terus belajar dari pesantren satu ke pesantren lainnya. Karena imam syafi'i pernah berkata "Barangsiapa yang tidak sanggup menahan lelahnya belajar maka kamu harus sanggup untuk menahan perihnya kebodohan". Pembelajaran itu dapat kita lakukan dimana saja baik di majelis ilmu, sekolah, dan bahkan pengalaman hidup dapat dijadikan pembelajaran. Belajar itu tidak memandang usia dikarenakan tua-muda harus terus belajar sampai napas itu terhenti. Dengan belajar juga dapat membantu kita dalam memilih informasi baik buruknya sesuai dengan perkembangan zaman karena ilmu adalah jendela dunia. Jendela dunia artinya dengan ilmu kita dapat menguasai, menjaga, mengelola, bahkan menghancurkan dunia maka tuntutlah ilmu yang dapat membawa kebaikan bagi semua orang.

Ketika usia Abdul Halim memasuki 21 tahun, Siti Mutmainah memanggil Abdul Halim untuk segera pulang ke Jatiwangi dikarenakan ibunya sudah mempersiapkan calon istri untuknya yang bernama Siti Murbiyah. Siti Murbiyah 
ialah seorang gadis cantik yang berusia 11 tahun. Siti Murbiyah adalah putri bungsu K.H. Muhammad Ilyas, yang ketika itu menjabat sebagai Penghulu Landraad Kabupaten Majalengka. Dari silsilah keturunan, Abdul Halim dengan Siti Murbiyah masih bersaudara dari pihak ibu. Beberapa bulan setelah menikah, Abdul Halim melaksanakan ibadah haji. Tak hanya melaksanakan ibadah haji, Abdul Halim juga menempuh pendidikan agama di mekkah. Dalam menuntut ilmu disana ia tidak sendirian melainkan bersama temannya yang bernama K.H. Mas Mansoer (Muhammadiyah), K.H. Abdul Wachab Chasbullah (Nahdlatul Ulama), K.H. Ahmad Sanoesi (Al-Itthadijatoel Islamijjah). Pada tahun 1911, Abdul Halim dijemput keluarganya agar segera kembali ke tanah air. Menurut Wanta, para penjemput Abdul Halim adalah ibu mertuanya yang bernama Ny. Djamilah dan kakak iparnya yang bernama H. Boerhanoel Asjikin. Dengan demikian, masa studi Abdul Halim hanya berlangsung kurang lebih tiga tahun (Hernawan \& Yanti, 2017b).

\section{Pemikiran dan Karyanya}

Pemikiran K.H. Abdul Halim antara lain dapat dilihat dari karya-karyanya, baik karya tulis maupun dalam bentuk kelembagaan. Ia dapat dikatakan sebagai ulama yang aktif berdakwah dan sekaligus seorang penulis yang produktif. Tulisan-tulisannya banyak yang sempat diterbitkan, baik dalam bentuk buku ataupun dalam bentuk brosur dan tulisan lepas di media massa. Sebagian tulisannya ada yang dipublikasikan khusus untuk kalangan anggota Persyarikatan Ulama (PU). Sayangnya, sebagian besar tulisannya terbakar sewaktu agresi militer Belanda kedua. Beberapa karya tulisnya yang dapat didata antara lain: a. Risalah Petunjuk bagi Sekalian Manusia; b. Ekonomi dan Koperasi dalam Islam; c. Ketetapan Pengajaran di Sekolah Ibtidaiyah Persyarikatan Ulama (sebagai Ketua Tim Penyusunan); c. Da'watul Amal; d. Tarikh Islam; e. Neraca Hidup; f. Risalah; g. Ijtimaiyah Wailajuha; h. Kitab Tafsir Tabarok; i. Kitab 262 Hadits Indonesia; dan j. Babul Rizqi. Aktivitas K.H. Abdul Halim, selain berorganisasi dalam Persjarikatan Oelama, juga aktif dalam di bidang dakwah dan pendidikan. Ia sering memberikan tablig dan membuka lembaga pendidikan. Tema utamanya adalah tentang hak-hak umat Islam dalam kehidupan berbangsa dan bernegara. K.H. Abdul Halim menyebut perjuangan memperbaiki kehidupan ekonomi dengan konsep Pembaharuan Ekonomi. Ia juga menulis sebuah buku yang berjudul Economie dan Cooperatie dalam Ajaran Islam yang isinya antara lain menjelaskan, bahwa koperasi dapat dijadikan sebagai salah satu cara berekonomi untuk meningkatkan kesejahteraan umat. Menurutnya, melalui koperasi, bukan hanya usrusan ekonomi yang dapat dilakukan, tetapi juga dapat dibina asas persaudaraan dan persatuan sesama anggotanya. Kedua asas ini merupakan prinsip-prinsip dasar untuk membangun kesetaraan umat dalam bidang ekonomi dan pada gilirannya dapat menghilangkan ketimpangan ekonomi. Ketimpangan dalam bidang ekonomi, menurut KH Abdul Halim, setidaknya disebabkan oleh dua hal, yaitu: (1) kebijakan ekonomi kolonial, dan (2) sifat malas dan boros yang menghinggapi perikehidupan kaum muslimin. Untuk itu, ia menawarkan salah satu cara penyelesaiannya yaitu : menanamkan kesadaran pada diri kaum muslimin agar berusaha dengan cara yang halal dan layak untuk memperbaiki kehidupan ekonomi, menumbuhkan tekad untuk dapat hidup sejajar atau kalau 
bisa melebihi bangsa lain. Selain itu juga dapat meningkatkan perekonomian kaum muslimin dengan cara yaitu : membiasakan hidup secara hemat, menambah dan meningkatkan pendapatan, serta mendirikan koperasi (Lektur et al., n.d.)

\section{Sejarah Berdirinya Santi Asromo}

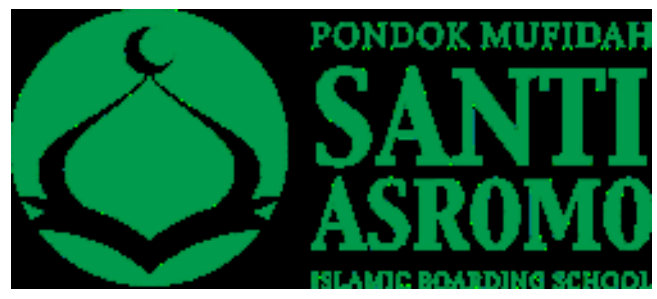

Gambar 2. Sumber: https://psbonlinesantiasromo.or.id/

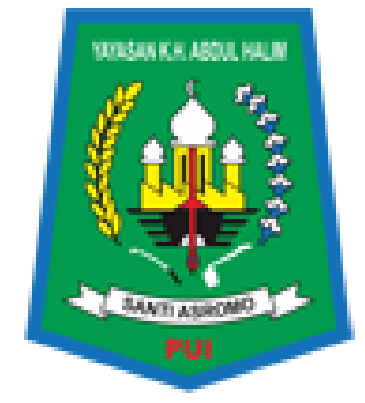

Gambar 2. Sumber: https://psbonlinesantiasromo.or.id/

\section{Masa 1931}

Pada Muktamar Perikatan Oelama (PO) ke IX di Majalengka KH Abdul Halim mencetuskan gagasan puncak untuk mendirikan lembaga pendidikan yang menjadikan peserta didiknya mampu mandiri di tengah masyarakat pada suatu tempat khusus. Program pendidikan tersebut dinamakan dengan konsep "Santi Asromo", dan KH Abdul Halim mendapat mandat untuk mewujudkannya.

\section{Masa 1932}

Tepatnya Bulan Romadlon 1350 H (Januari 1932) KH. Abdul Halim mendapatkan tanah wakaf seluas 2 bau 40 bata yang cocok dan sesuai untuk mendirikan sebuah Pondok Pesantren yang saat itu akan dinamakan "Santi Asromo" dari seorang aghnia di desa Ciomas, M. Ardja Subrata putra teruta dari M. Ardja Winata. Diawali dengan pembukaan lahan padang ilalang pada sebuah bukit tandus Reumadengkeng / Sukamanah, KH.Abdul Halim membangun "surau" kecil dari kayu berdindingkan anyaman bambu dan beratapkan ilalang, sebagai cikal bakal Pondok SantiAsromo. Santi Asromo dibawah binaan langsung K.H. Abdul Halim dengan lembaga pengasuhan santri Linggo Sarojo di bawah pimpinan Moh. Thoha Halim (putra tertua KH Abdul Halim Alm) dengan konsentrasi mempersiapkan santri yang sudah tamat Kweek School PO di Majalengka untuk melanjutkan menjadi santri mandiri dapat mengisi setiap 
lapangan kegiatan penyelenggara negara maupun menciptakan lapangan pekerjaan tersendiri.

\section{Masa 1932-1935}

Para santri Kweek School PO kelas III dan IV secara terjadwal pergi dan menetap 2 hari dalam seminggu di Santi Asromo untuk praktek perkebunan, pertanian dan peternakan.

\section{Masa 1936-1958}

Diawali sekolah formal dengan sistem boarding school yang dilengkapi berbagai kegiatan pertanian, perkebunan dan perdagangan, membuat percontohan budidaya tanaman sebagai proyek inti dan masyarakat sekitar menanam tanaman, pembuatan tenun, rajut, pembudidayaan tanaman obat, selain itu di laksanakan pula peternakan kambing PE, dan ayam. Selain itu pada tahun 1958, didirikanlah Poliklinik di Santi Asromo, yang kemunginan poliklinik pertama di Pondok Pesantren di Majalengka.

\section{Masa 1958}

SRI berafiliasi ke Departemen Agama sesuai program pemerintah, berganti nama menjadi MWB [Madrosah Wajib Belajar] dengan Kepala MWB Pertama Ustd. Amir dari desa Cicalung.

\section{Masa 1962}

Tepatnya tanggal 3 Djulhijjah $1381 \mathrm{H}$ atau 7 Mei 1962 M, hari Senin Pukul 15.05. Hadrotu Sjaikh K. H. Abdul Halim berpulang ke rahmatullah, dan yang menggantikan beliau adalah putra dan menantu beliau Fatimah Halim (putri ke 2 beliau) dan KH. Abdul Qohar

\section{Masa 1971}

Tahun 1971 MWB berganti nama menjadi MI [Madrosah Ibtidaiyah] sampai sekarang.

\section{Masa 1962}

Sepeninggal K.H. Abdul Halim, atas gagasan Ibu Fatimah Halim beserta suami K.H. Abdul Kohar merintis berdirinya Sekolah Menengah Pertama Swasta [SMP Swasta Prakarja Santi Asromo], dengan pimpinan Sekolah pertama adalah putra ke tiga beliau K.H. Aziz Halim, dilanjutkan oleh KH. Cholid Fadullah, K. Amas Turmudzi, Drs. H. Muhamad Suji dan Drs, H. Sohib (Sampai dengan saat ini)

\section{Masa 1968}

Linggo Sarojo sebagai lembaga yang menaungi institusi pendidikan diganti dengan institusi formal sesuai dengan peraturan perundang - undangan pada masa itu menjadi Yayasan K.H. Abdul Halim, dengan ketua Yayasan Pertama adalah K.H. Taufiq Halim (Alm), di lanjutkan oleh H.M Wanta (Alm), 
KH. Cholid Fadullah dan sejak tahun 2008 oleh H. Ido Nurzaini Aziz (Cucu KH. Abdul Halim) sampai sekarang.

\section{Masa 1992}

Pada masa kepemimpinan Yayasan K.H. Abdul Halim dipegang oleh K.H. Cholid Fadlullah, didirikanlah institusi pendidikan menengah atas SMA Prakarya dengan kepala sekolah pertama KH Taufik Halim SH, kemudian Shijamudin, BA dan Drs. Masjhudi (sampai dengan sekarang).

\section{Masa 2008 s/d 2010}

Saat ini Yayasan K.H. Abdul Halim dipimpin oleh H. Ido Nur Zaeni Aziz. dibawah kepemimpinan beliau Visi Santi Asromo ingin kembali pada khitah 1932 dengan dicanangkannya program Santi Asromo Boarding School, sejak tahun 2010 dengan target pada tahun 2015 sudah berjalan efektif.

\section{Masa 2010}

Pelaksanaan Boarding School seluruh santri di Pondokkan mulai berjalan di awali dari kelas 7 dan 10 selain itu kita merintis untuk santri dari daerah sekitar yang tidak berkesempatan untuk mondok di beri fasilitas kelas parallel (https://santiasromo.or.id/tentang-kami/sejarah-berdiri, diakses pada 5 Mei 2020 pukul 09.17)

\section{Gerakan Politik KH. Abdul Halim}

\section{a. Masa Pemerintahan Hindia Belanda}

Sejak berdiri pada 16 Mei 1916, Persjarikatan Oelama telah melaksanakan kongres tercatat kongres ini diadakan pada April 1938 yaitu kongres ke-15. Persjarikatan Oelama adalah organisasi yang berasaskan politik-agama. Gerakannya mirip dengan Partai Sarekat Islam Indonesia (PSII), namun jauh lebih moderat. organisasi pergerakan ini telah berhasil melahirkan regenerasi pimpinan. Pada kongres itu terpilih sebagai Voorzitter Hoofdbestuur, seorang tokoh muda dari Kuningan Ahmad Ambary. Ia dibantu oleh tokoh muda lainnya, masing-masing: Asjikin Hidajat sebagai Secretaris (Sekretaris) dan Abdoel Wahab sebagai Penningmeester (Bendahara). Sementara Abdul Halim didaulat sebagai Adviser (Penasehat) Persyarikatan Oelama.

b. Masa Pemerintah Pendudukan Jepang

MIAI (Madjelis Islam A'la Indonesia) kegiatan yang dipandang kurang memuaskan pemerintah Pendudukan Jepang, kemudian dibubarkan pada Oktober 1943. Sebagai penggantinya, lalu dibentuk organisasi Masjumi (Madjelis Sjoero Moeslimien Indonesia) yang disahkan oleh Gunseikan pada 22 November 1943. K.H. Hasjim Asj'ari dari NU (Nahdlatul Ulama) kemudian ditunjuk sebagai Ketua Umum untuk pertama kalinya. Badan ini dikenal dengan BPUPKI (Badan Penyelidik UsahaUsaha Persiapan Kemerdekaan Indonesia). Dalam badan itu, Abdul Halim termasuk kelompok 62 bersama dengan Radjiman Wedyodiningrat. Sebuah sejarah yang tidak dapat diabaikan, karena BPUPKI merupakan organisasi yang berfungsi untuk merencanakan agar Indonesia dapat merdeka tanpa adanya campur tangan negara lain melainkan usaha atas bangsanya sendiri. Perserikatan Umat Islam (PUI) yang 
diwakili oleh Abdul Halim telah ikut memberikan sumbangan bagi perumusan kemerdekaan Indonesia.

c. Masa Indonesia Merdeka sampai Akhir Hayat

Setelah Indonesia memproklamirkan kemerdekaannya pada 17 Agustus 1945, dijumpai sejumlah informasi, bahwa aktivitas Abdul Halim tidak berhenti sampai di sana. Pada September 1945, tercatat ia diangkat menjadi anggota KNID (Komite Nasional Indonesia Daerah). di Karesidenan Cirebon. Namun demikian, proklamasi kemerdekaan Indonesia tidak lantas mendapatkan pengakuan dari pemerintah Belanda. Mereka bahkan bermaksud menjadikan kembali wilayah Nusantara sebagai bagian dari kerajaan mereka. Hal itu ditunjukkan dengan adanya serangkaian agresi militer. Agresi militer pertama berlangsung pada Juli 1947 (Agresi Militer I), sedangkan agresi militer kedua berlangsung pada Desember 1948 (Agresi Militer II). Agresi militer Belanda, pada perkembangannya ternyata tidak hanya fokus pada bidang militer, tetapi juga bidang agama dan politik. Dalam bidang agama, sebut saja misalnya, guna memecah-belah bangsa Indonesia yang baru terbentuk, mereka menyusun gerakan sparatis yang bersifat millenaristis. Hal itu seperti terjadi di Burujulwetan, Jatiwangi pada 1947 di bawah pimpinan Haji Sarip. Sementara dalam bidang politik, pasukan militer Belanda berusaha menerapkan konsep negara federal. Untuk mencapai tujuannya, mulai didirikan beberapa negara bagian. Di Jawa Barat, misalnya, berdiri Negara Pasundan. Sebagai akibat dari agresi militer yang dilakukan oleh pemerintahan NICA (Ne derland Indies Civil Administration), di Pulau Jawa terjadi eva kuasi rakyat secara besar-besaran. Peristiwa tersebut menyebabkan rakyat harus berjuang secara gerilya (Hernawan \& Yanti, 2017b).

\section{Penghargaan dan Tanda Jasa}

Abdul Halim termasuk di antara tokoh nasional yang mendapat apresiasi pemerintah R.I. Sekretariat Jenderal Dewan Tanda-tanda Kehormatan RI.,117 menyebutkan beberapa penghargaan dan tanda jasa yang disematkan kepada Abdul Halim. Pertama, tanda penghargaan sebagai Oelama Pejoeang dari Yayasan Asih Fatmah. Kedua, Abdul Halim juga termasuk di antara tokoh nasional yang mendapat anugerah Bintang Mahaputera Utama dari pemerintah Republik Indonesia dengan No. 048/TK/Tahun 1992. Ketiga, atas sejumlah pemikiran dan gerakan politik yang ditorehkan Abdul Halim, berdasarkan hasil sidang Badan Pembina Pahlawan Pusat pada 2008 dan hasil sidang Dewan Tanda-Tanda Kehormatan RI 30 Oktober 2008, serta Keputusan Presiden Nomor 041/TK/ TH. 2008 pada tanggal 6 November 2008 Presiden menganugerahkan Gelar Pahlawan Nasional dan Bintang Mahaputera Adipradana (Hernawan \& Yanti, 2017a).

\section{Memperkenalkan sejarah kepada peserta didik dengan menggunakan metode pembelajaran}

Menurut Hans Daeng permainan ialah bagian yang tidak terbatas dari kehidupan anak dan permainan merupakan bagian integral dari proses pembentukan kepribadian anak. Selanjutnya Andang Ismail menuturkan bahwa permainan ada dua pengertian. Pertama, permainan ialah kegiatan bermain yang murni mencari kesenangan tanpa mencari menang atau kalah. Kedua, permainan ialah kegiatan 
bermain yang dilakukan dalam rangka mencari kesenangan dan kepuasan, namun ditandai pencarian menang - kalah. Game berfungsi untuk menghibur, biasanya game disukai oleh anak - anak hingga orang dewasa. Game itu penting untuk perkembangan otak anak yaitu untuk meningkatkan konsentrasi dan melatih untuk memecahkan masalah dengan tepat dan cepat karena dalam game terdapat berbagai masalah yang menuntut kita untuk menyelesaikannya dengan cepat dan tepat. Tetapi game bisa merugikan anak apabila anak sudah kecanduan game maka akan lupa dengan waktu dan akan mengganggu kegiatan yang sedang anak lakukan (Setiawan et al., 2015).

Dengan cara mempelajari sejarah para pahlawan, maka dapat meningkatkan jiwa nasionalisme dan patriotisme. Para guru semestinya memberikan pelajaran yang menyenangkan terkait sejarah para pahlawan indonesia seperti KH. Abdul Halim. Pembelajarannya dapat berupa menciptakan game/permainan dalam / luar kelas per kelompok lalu masing-masing kelompok menceritakan hasil diskusi ke temantemannya dengan cara kelompok pemberi materi menyebutkan ciri-ciri dari pahlawan lalu kelompok lain menyebutkan siapa pahlawan yang dimaksud. Selain permainan itu menyenangkan anak-anak pun mendapatkan pengetahuan melalui ejarah para pahlwan. Selain dilakukannya permainan, para guru dapat melakukannya dengan meceritakan sejarah para pahlwan di kelas lalu menunjuk anak untuk menceritakan kembali secara singkat terhadap yang sebelumnnya sudah diceritakan oleh gurunya.

Berhubung dengan kemajuan ilmu pengetahuan dan teknologi maka dapat juga membuat aplikasi di android dengan memperkenalkan sejarah para pahlawan yang ada di Indonesia karena dengan kita tahu mengenai pahlawan maka peserta didik dapat meningkatkan jiwa nasionalisme dan patriotisme terhadap para pahlawan yang telah gugur, selain itu peserta didik tidak melupakan jasa pahlawan yang rela berkorban membangun negeri ini agar tetap kokoh berdiri (Rupa et al., 2019).

\section{KESIMPULAN}

KH. Abdul Halim ialah seorang pahlawan nasional namun ia pun seorang ulama dan berhasil mecetak para ulama. KH. Abdul Halim tidak sekolah formal karena hanya orang terhormat yang dapat bersekolah di sekolah formal, namun ia mondok di berbagai pondok pesantren. Awalnya ia mondok di Pesantren Cideres, Dawuan. Ketika usianya mencapai 10 tahun ia sudah dapat membaca al-Qur'an dengan baik sesuai dengan tajwid dan tartil. Ketika berada di pesantren Cideres ia pun bergaul dengan teman-temannya. Berkat pergaulannya ia pun berlatih membaca dan menulis huruf latin serta bahasa Belanda kepada Van Verhoeven. Pendidikan alQur'an di pesantren Kampung Cideres diselesaikan Abdul Halim dalam satu tahun. Setelah lulus, ia tak berhenti belajar melainkan ia tetap terus belajar dari pesantren satu ke pesantren lainnya. Semasa hidupnya ia menghasilkan banyak karya yaitu ia membuat buku-buku, kelembagaan. Beberapa karya tulisnya yang dapat didata antara lain: a. Risalah Petunjuk bagi Sekalian Manusia; b. Ekonomi dan Koperasi dalam Islam; c. Ketetapan Pengajaran di Sekolah Ibtidaiyah Persyarikatan Ulama (sebagai Ketua Tim Penyusunan); c. Da'watul Amal; d. Tarikh Islam; e. Neraca Hidup; f. Risalah; g. Ijtimaiyah Wailajuha; h. Kitab Tafsir Tabarok; i. Kitab 262 Hadits Indonesia; dan j. Babul Rizqi. Ia juga menulis sebuah buku yang berjudul Economie 
dan Cooperatie dalam Ajaran Islam yang isinya antara lain menjelaskan, bahwa koperasi dapat dijadikan sebagai salah satu cara berekonomi untuk meningkatkan kesejahteraan umat. Organisasi yang ia buat yaitu PUI (Perserikatan Ulama Indonesia). Sebagai pendiri Pergerakan Umat Islam, Abdul Halim, Ahmad Sanusi, dan Syamsuddin juga berjasa dalam memperjuangkan kemerdekaan Indonesia Perserikatan Ulama Indonesia ini membangun program pendidikan yaitu Santi Asromo yang lokasinya berada di Majalengka, Jawa Barat. Ketika usia KH. Abdul Halim memasuki 21 tahun ia pun menikah dengan Siti Murbiyah. Beberapa bulan menikah, KH. Abdul halim melaksanakan haji. Tak hanya melaksanakan haji melainkan ia juga mengemban pendidikan disana. Dengan cara mempelajari sejarah para pahlawan, maka dapat meningkatkan jiwa nasionalisme dan patriotisme. Para guru semestinya memberikan pelajaran yang menyenangkan terkait sejarah para pahlawan indonesia seperti KH. Abdul Halim. Pembelajarannya dapat berupa menciptakan game/permainan dalam / luar kelas per kelompok lalu masing - masing kelompok menceritakan hasil diskusi ke teman-temannya dengan cara kelompok pemberi materi menyebutkan ciri-ciri dari pahlawan lalu kelompok lain menyebutkan siapa pahlawan yang dimaksud. Selain permainan itu menyenangkan anak-anak pun mendapatkan pengetahuan melalui ejarah para pahlwan. Selain dilakukannya permainan, para guru dapat melakukannya dengan meceritakan sejarah para pahlwan di kelas lalu menunjuk anak untuk menceritakan kembali secara singkat terhadap yang sebelumnnya sudah diceritakan oleh gurunya. Selain itu dapat juga membuat aplikasi berbasis android dengan konten Para Pahlawan di Indonesia.

\section{DAFTAR PUSTAKA}

Ariesta, I. (2017). Edugrafis pahlawan nasional Indonesia untuk pendidikan kewarganegaraan sekolah dasar tahun ke-1. Dimensi DKV, 2(2), 167-184.

Ii, P., Purnomo, B., \& Syarifudin, A. (2018). IMPERIALISME BARAT SISWA SMA NEGERI 6 KOTA JAMBI OLEH : ANDI SYAHPUTRA A1A214084. 1-15.

Kh, A. B., \& Alie, N. (1914). Ali Anwar, Kemandirian Ulama Pejuang KH Noer Alie, (Bekasi: Yayasan Attaqwa, 2015), hal.1. 1.

Marker, D., \& Indonesia, U. (2015). Metodologi yang digunakan dalam penulisan tugas akhir ini adalah dengan metode prototype. Metode Prototype merupakan metode pengembangan perangkat lunak yang memodelkan dari sistem kerja suatu perangkat lunak yang belum lengkap dari pihak user. Para pen. 43-50.

Sejarah, J., Sosial, F. I., \& Semarang, U. N. (2014). Persepsi Siswa Tentang Keteladanan Pahlawan Nasional Untuk Meningkatkan Semangat Kebangsaan. Indonesian Journal of History Education, 3(1), 1-5. 